\title{
Is Total Parenteral Nutrition (TPN) an Evil in Trauma Patients?
}

\author{
Ilya Kagan $^{1} \cdot$ Miriam Theilla $^{1} \cdot$ Pierre Singer $^{1}$
}

Published online: 22 April 2016

(C) Springer International Publishing AG 2016

\begin{abstract}
The use of parenteral nutrition has been progressively decreasing over the past 30 years, and it has been considered as harmful while enteral feeding has been preferred for critically ill trauma patients, including for head trauma patients. However, the use of enteral feeding is associated with underfeeding while the use of parenteral nutrition can create complications due to overfeeding (infections, increased length of stay, length of ventilation, increased liver tests). Measuring energy expenditure by indirect calorimetry enables more accurate energy needs and calorie targets can be optimized. Formulas with higher protein content allow increased protein administration. In case of gastrointestinal intolerance, parenteral nutrition is an efficient alternative route to reach optimal targets. This route may improve clinical outcome. The use of parenteral nutrition has recently been shown to be safe if not given in excess, challenging the theory that TPN should be avoided. A reevaluation of the use of parenteral nutrition has to be performed to decrease calorie and nitrogen deficits in critically ill trauma patients.
\end{abstract}

Keywords Parenteral nutrition · Trauma and nutrition · Critical care

This article is part of the Topical Collection on Nutrition After Severe Trauma

Pierre Singer

Psinger@clalit.org.il

1 Department of Intensive Care and Institute for Nutrition Research, Rabin Medical Center, Beilinson Hospital, Sackler School of Medicine, Tel Aviv University, Jabotinsky Street, Petah Tikva 49100, Israel

\section{Introduction}

With the increased use in early enteral nutrition (EN) in critically ill patients and in particular in trauma patients [1-3], the prescription of parenteral nutrition $(\mathrm{PN})$ has decreased. This was reinforced by the theory of translocation that PN could favor bacteremia [4]. Rhee et al. [5] showed in a retrospective study that between 2000 and 2005 that total parenteral nutrition (TPN) prescription decreased from 26 to $3 \%$ suggesting a disappearance of TPN, without effect on mortality but with a decrease in morbidity. Pinsky and Marik added more hesitations regarding TPN safety in an editorial [6], arguing that the adverse sequelae associated with TPN resulted from a combination between not feeding the bowel and metabolic, endocrine, immunological, and infective complications associated with TPN. Additionally, after the 2011 article from Casaer et al. [7•] comparing early to late parenteral nutrition in critically ill patients which described early supplemental PN as harmful, a further decrease occurred [8]. The purpose of our review is to understand why clinicians have decided to prescribe less PN, how recent studies reversed the approach to PN, and how to optimally feed the trauma patients.

\section{How parenteral nutrition lost popularity?}

In 1997, Battistela et al. [9] enrolled 57 trauma patients receiving PN in a study comparing PN with or without intravenous lipid emulsion (soybean based). Significant differences were observed such as a longer period of mechanical ventilation, longer ICU and hospital stay, as well as an increased number of infectious complications (72 versus 39) in the lipid group receiving also more calories by design of the study. It was not clear if the effects observed in the lipid group were related to the proinflammatory nature of the lipids or to the intentional excess in calories administered. In an editorial entitled "Death 
by parenteral nutrition," Pinsky and Marik [6] described all the deleterious effects associated to parenteral nutrition mainly increase in infectious complications, liver enzyme abnormalities, length of ventilation, and length of ICU stay [10-12]. A further study found that in critically ill trauma victims, TPN administration was independently associated with late ARDS [13]. However, these complications were related not only to the route of administration but also to the large calorie prescription such as in the Dissanaike study [14]. In this study, the risk of bloodstream infections was associated with increased parenteral caloric intake. In 200 consecutive patients included, 78 developed a blood stream infection, but in the group which developed the infections, the calorie intake was from $20 \mathrm{kcal}$ up to 70 (!) $\mathrm{kcal} / \mathrm{kg}$ with a mean intake of $35 \mathrm{kcal} / \mathrm{kg}$ much higher than that of the recommendations. Grau et al. described liver dysfunction associated with parenteral nutrition [15] in a prospective cohort study of incidence in 40 intensive care units. In the multivariate analysis, liver dysfunction was associated not only with parenteral nutrition but also with excessive calorie intake above $25 \mathrm{kcal} / \mathrm{kg}$. Ziegler [16] described the complications associated with parenteral nutrition related to excess calories inducing hypercapnia and respiratory insufficiency and increased length of ventilation, hyperinsulinemia related to excess carbohydrate, and azotemia related to excess amino acid. In fact, all the complications associated to PN were related mainly to the calorie load and not to the route. Despite these facts and due to many publications comparing parenteral to enteral nutrition but not in an isocaloric aspect, many scientific societies recommend not prescribing parenteral nutrition in the early phase of acute illness (up to 7-10 days after admission). Furthermore, the EPaNIC study [7•] compared early to late administration of supplemental parenteral nutrition (SPN) and demonstrated that early SPN was associated with increase in infectious complications and prolonged length of ventilation. Both these complications are well known to be related to overfeeding. Leuwen group used the ESCIM 1998 equation to define the calorie target of the patients included in the study. This is the equation proposing the highest calorie prescription, and it is not surprising to see the patients receiving early SPN having more infection and longer length of ventilation.

\section{How parenteral nutrition regained safety?}

Many studies related to parenteral nutrition did not take into account the fact that PN is indicated when the gastrointestinal tract is failing or enteral feeding is not reaching the target calories. Comparing a group receiving TPN secondary to GI failure to a group tolerating enteral feeding could lead to wrong conclusions. In addition, most of the studies of the recent years are underfeeding ICU patients even in the control groups also leading to false conclusions. When the calorie target was defined and the indications for enteral or parenteral nutrition not taken into account in the study, Harvey et al. [17••] demonstrated in the CALORIES study that there was no significant difference in terms of infection, length of ventilation, or length of ICU stay between the EN and PN groups receiving the same amount of calories and protein. The only difference was a lower hypoglycemia rate in the PN group but an increase liver dysfunction. Doig et al. [18•] showed in a prospective randomized study comparing early PN to late PN in a population of patients not tolerating enteral feeding that PN was as safe as not administrating PN and did not show any difference in rate of complications. Heiddeger et al. [19•] compared early SPN to enteral feeding only in ICU patients failing to achieve calorie target at day 3. SPN calories were prescribed according to indirect calorimetry (IC) measurements, and not according to predictive equations. IC has been recommended by ESPEN and ASPEN [20, 21] since predictive equations have been shown to be inaccurate [22]. Results showed that infection rate was decreased in the SPN group compared to the enteral only group, differing from the EPaNIC results. In the TICACOS study [23•] performed by our group, patients receiving enteral associated or not to parenteral nutrition according to indirect calorimetry had a better hospital survival than did the patients fed following equation and underfed when referring to their indirect calorimetry measurements.

Another aspect related to PN that decreased its popularity was the use of soybean-based lipid emulsions. These intravenous fat emulsions (IVFEs) are believed to increase inflammation and infection rate as well as decrease immunity [24]. In the last decade, medium chain triglycerides, lipid emulsions based on omega 9 fatty acids as well as enriched in omega 3 fatty acids have been developed and found to be safe. Using them in critical illness decreased rates of infectious and liver dysfunction complications and may also decrease length of ICU stay [25]. The use of these new lipid emulsions also decreased the number of complications related to PN [24].

\section{Who should receive parenteral nutrition?}

All critically ill trauma patients are considered to be at risk of malnutrition according to the screening test NRS 2002 [26] and those who will stay more than 2 days should receive nutritional support [20]. After appropriate resuscitation and stabilization, enteral feeding should be initiated within $48 \mathrm{~h}$ with an attempt to reach the calorie and protein target. Most trauma patients will tolerate enteral feeding and do not require $\mathrm{PN}$. Therefore, there are only few studies on the use of parenteral nutrition in trauma. Even in head trauma patients who have been considered to be difficult to feed, early enteral feeding is feasible and is associated with reduction in mortality, poor outcome, and infection rate $[27,28 \bullet \bullet]$. Gastrointestinal intolerance should be assessed and has been associated to increased mortality [29]. In these conditions and if the patient 
is malnourished (BMI $<18.5$ or weight loss more than $10 \%$ regardless to time or $5 \%$ in the last 3 months) [30], parenteral nutrition should be started (see Fig. 1). In many cases, enteral nutrition is started but caloric target is not achieved in the first few days. Negative energy balance has been associated with increased complication rates [31] and survival is higher if calorie intake is close to $80 \%$ of the prescribed energy [32]. Therefore and despite a lack of consensus between experts [7•, 33], ESPEN guidelines recommend to start supplemental parenteral nutrition after 3 days for all patients if enteral nutrition do not reach the target [20]. We conclude that if the EPaNIC study showed that early PN was associated with increased morbidity, others [18•] did not confirm these findings, and Hardley [17 •.] demonstrated that PN was not more harmful than enteral feeding in a large population of critically ill patients.

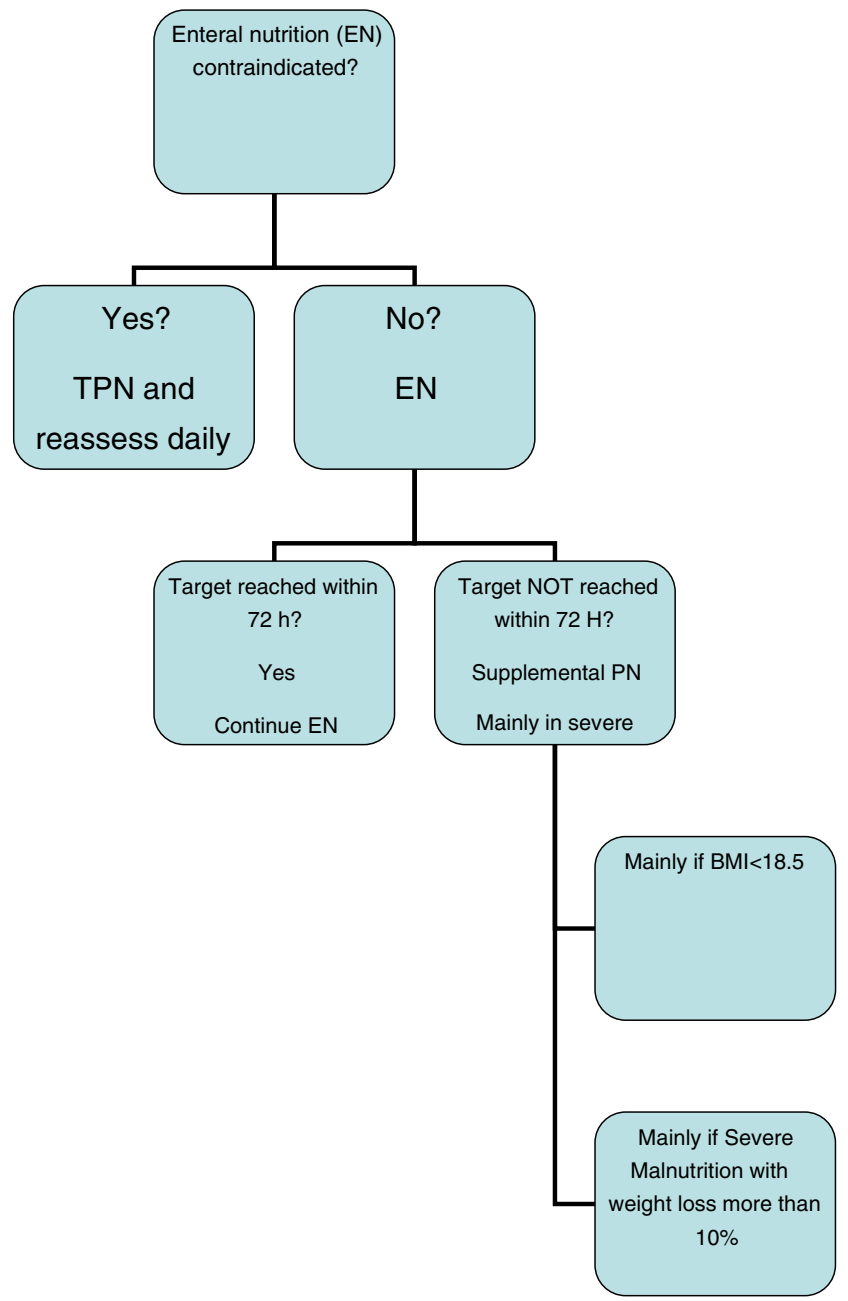

Fig. 1 Flow chart supporting decision making if enteral nutrition is not achievable in critically ill trauma patients. $A C S$ is abdominal compartment syndrome, $U G I$ is upper gastrointestinal, GIT is gastrointestinal tract, $T P N$ is total parenteral nutrition, and $B M I$ is body mass index in $\mathrm{kg} / \mathrm{m}^{2}$

\section{How much?}

Most of the figures published by Kinney and Long [34] in the 70 s are not comparable to the patients we treat today. Surgery, monitoring, sedation, and analgesia have tremendously changed. Traumatic injury induces hypermetabolism and the degree of hypermetabolism can be variable, depending on the type of injury, the degree of inflammation, body composition, age, and treatment regimens. To estimate metabolic rate in some types of injury, predictive equations have been published. Some of these equations have been tested in validation studies. For other types of injury, equations do not exist. Some expert panels have recommended measuring instead of estimating metabolic rate, though studies have not been performed to determine whether clinical outcome is affected by the method used to determine energy requirements [35]. The energy expenditure of trauma patients is usually higher than the basal metabolic rate of normal subjects of same anthropometry and may be highly variable [36]. In our center, we [37] followed the measured energy expenditure (304 measurements) of 50 multiple trauma patients for 14 days and found that REE was significantly higher (up to $50 \%$ at day 6 and days 12-13) than predictive equations such as Harris Benedict equation but that there was also a significant day-by-day variation (Fig. 2). Head trauma (isolated or combined with other injuries) is also associated with increased energy expenditure, but sedation is decreasing these measurements [38]. From a large evaluation of enteral nutrition adequacy derived from 12 , 573 critically ill patients [39•], 1279 trauma patients were analyzed and were found to receive only $57 \%$ of the prescribed calories showing the difficulties of feeding critically ill trauma patients enterally. In addition, the prescribed calories are based on predictive equations that are inaccurate in 40 to $60 \%$ of the cases, further increasing the risks of under or overfeeding. These findings stress the need for indirect calorimetry measurement at least once to determine the energy requirements [20].



Fig. 2 Variations of measured resting energy expenditure (in kcal/day) of 50 multiple trauma ventilated patients for 14 days. Bars indicate the percent of REE above the predictive value obtained by Harris Benedict equations 


\section{Macronutrients, vitamins, and trace elements}

The main macronutrients of parenteral nutrition are amino acid, lipids, and carbohydrates. Posttraumatic hyperglycemia is common and occurs mainly due to increased hepatic output of glucose [40]. Additional carbohydrate load is associated with glucose intolerance and this may be exacerbated by administration of PN. Administration of insulin is often required for glycemic control (target 150 to $180 \mathrm{mg} / \mathrm{dL}$ ) [20, 21].

Lipids are an obligatory component of the nutritional regimen for support of the trauma patient. Thirty to forty percent of non-protein calories should be provided as fat. Enteral fat composition can be enriched with eicosapentaenoic acid (EPA) and GLA lipid emulsions. We assessed the effects of an enteral nutrition formula enriched with fish oil (eicosapentaenoic acid), gamma-linolenic acid, and antioxidants on respiratory parameters in patients with severe multiple trauma requiring mechanical ventilation [41•]. We did not find significant benefit for the preemptive use of the study formula compared to control formula. This may be explained by the fact that EPA content in the membrane of trauma patients was very low from admission and EPA administration hardly succeeded to normalize the values and almost never succeeded to reach supranormal values [41•]. Administration of IV fat emulsions included in the PN regimen is a matter of discussion in the first week of intensive care according to the recent ASPEN guidelines [21]. However, the use of IV FE in the USA is limited to soybean-based lipid emulsions while in Europe and other places in the world, olive oil and fish oilbased IVFE are of common use, increasing the safety of the administration. In two large meta-analysis [25, 42], IV fish oilbased lipids were shown to improve length of stay and infection rate in both surgical and intensive care populations but did not influence mortality. Therefore, it is reasonable to recommend the use of these lipids when PN is recommended at the daily dose of 0.7 to $1.2 \mathrm{~g} / \mathrm{kg}$.

The protein metabolism of severe trauma patients is very similar to the metabolism of patients with severe sepsis [43]. Despite the fact that trauma injury patients are usually catabolic, protein needs after traumatic injury continue to be debated [35]. ESPEN guidelines recommend amino acid administration at a dose of $1.2-1.5 \mathrm{~g} / \mathrm{kg}$ ideal body mass (if normal renal and hepatic function) for all ICU patients [20]. A large systematic review studied the effects of various protein intakes on outcomes in critical illness and concluded that high protein administration was associated with improved nitrogen balance, protein turnover, and better clinical outcomes. They recommended up to $2 \mathrm{~g} / \mathrm{kg}$ ideal body weight [44]. Formulas containing high protein content are now commercially available.

Enteral glutamine is recommended in trauma and burn patient $[20,21]$. IV glutamine has been recommended to be administered in PN [20], but a recent large study from
Heyland et al. [45] failed to show improvement in clinical outcomes in critically ill patients. In this study, where very high doses of glutamine were administrated enterally and parenterally, glutamine administration was associated with an increase in mortality among critically ill patients suffering from multiorgan failure, mainly renal and liver failure [45]. Some studies have investigated the role of IV glutamine specifically in trauma patients but have failed to show benefit. Perez-Barcena et al. showed no effect of glutamine on expression or functionality of Toll-like receptors in trauma patients in ICU [46]. Recently, Perez-Barsena et al. again did not find any beneficial effect of glutamine during 5 days of administration in terms of prevention of new infections. Low levels of glutamine remain unchanged despite administration and were associated as worse outcome [47]. However, Wischmeyer [48], in a meta-analysis including critically ill patients and trauma patients but excluding the recent Heyland study, concluded that IV glutamine should be added in PN in patients without renal and hepatic failure. The recent ASPEN guidelines [21] do not recommend the use of IV glutamine in these patients.

Severely injured patients suffer from intensive oxidative stress as part of the inflammatory process. Animal models of severe multiple trauma show severe alteration in trace element (TE) levels. Appropriate TE supplementation improves the TE concentration and reduces the mortality related to multiple organ failure in these models [49]. Berger et al. did not show any beneficial effect of IV TE, vitamins, and glutamine infusion in critically ill patients after cardiac surgery, trauma, or subarachnoid hemorrhage, but in surviving trauma patients, length of hospital stay was shorter [50]. In another study, early IV TE supplementation was associated with improved recovery, reduced infectious complications (particularly nosocomial pneumonia), normalized thyroid function, normalized skin tissue levels, improved wound healing, and shortened hospital stay [51]. ESPEN guidelines recommend TE supplementation in all TPN infusions. Based on the same studies, recently published ASPEN guidelines suggest that antioxidant vitamins and trace elements may improve outcome in trauma and severe burn patient and recommend adding TE to PN [21].

\section{Monitoring}

Parenteral nutrition requires close monitoring for several complications such as refeeding syndrome, overfeeding, hyperglycemia, parenteral nutrition-associated liver disease (PNALD), electrolyte disturbance, and catheter-related infections. Risk of refeeding syndrome associated with malnutrition is higher in PN than in EN [21]. Hyperglycemia requires strict glucose control. Parenteral nutrition-associated liver disease (also known as TPN-induced cholestasis) is frequently associated to PN administration. Last year's incidence of severe forms of 
PNALD reduced but frequency of mild forms of liver dysfunction was met in $40 \%$ of patients [52]. High suspicion and close monitoring are keys to prevent this complication. The incidence of central line-associated blood stream infection (CLABSI) has decreased due to implementation of preventive protocols. In the CALORIES study, no difference in incidence of blood stream infection was found between enteral nutrition and parenteral nutrition groups $[17 \bullet \bullet]$.

\section{Conclusions}

A coherent approach of nutritional support in trauma patients includes the determination of calorie and protein goals. Enteral feeding should be used preferentially and if not achievable, physicians should use parenteral nutrition avoiding under and overnutrition. The calorie target should be obtained by indirect calorimetry and if not available, by a predictive equations such as the Penn State University Equation. Protein should be administered as $1.5 \mathrm{~g} / \mathrm{kg}$. Glutamine can be considered if there is no organ failure diagnosed and fish oil can decrease length of stay in the ICU. Close monitoring should be organized to obtain close glucose control and calorie control.

\section{Compliance with Ethical Standards}

Conflict of Interest Drs. Kagan, Theilla, and Singer declare that they have no conflicts of interest.

Human and Animal Rights and Informed Consent This article does not contain any studies with human or animal subjects performed by any of the authors.

\section{References}

Papers of particular interest, published recently, have been highlighted as:

- Of importance

•- Of major importance

1. Moore FA, Feliciano DV, Andrassy RJ, et al. Early enteral feeding, compared with parenteral, reduces postoperative septic complications: the results of a meta-analysis. Ann Surg. 1992;216(2):17283.

2. Li J, Kudsk KA, Gocinski B, Dent D, Glezer J, Langkamp-Henken B. Effects of parenteral and enteral nutrition on gut-associated lymphoid tissue. J Trauma. 1995;39:44-51.

3. Doig GS, Heighes PT, Simpson F, Sweetman EA, Davies AR. Early enteral nutrition, provided within $24 \mathrm{~h}$ of injury or intensive care unit admission, significantly reduces mortality in critically ill patients: a meta-analysis of randomized controlled trials. Intensive Care Med. 2009;35(12):2018-27.
4. Marshall JC, Charbonnay E, Goanzalez PD. The immune system in critical illness. Clinics Chest Med. 2008;29:605-16.

5. Rhee P, Hadjizacharia P, Trankiem C, et al. What happened to total parenteral nutrition? The disappearance of its use in a trauma intensive care unit. J Trauma. 2007;63(6):1215-22.

6. Marik PE, Pinsky M. Death by parenteral nutrition. Intensive Care Med. 2003;29:867-9.

7. Casaer MP, Mesotten D, Hermans G, et al. Early versus late parenteral nutrition in critically ill adults. N Engl J Med. 2011;365:50617. A large study comparing early to late supplemental parenteral nutrition in a heterogeneous ICU population and claiming that early parenteral nutrition may be harmful in this setting.

8. Bendavid I, Singer P, Theilla M, Hiesmayr M et al.: Nutrition day in the Intensive Care: a prevalence study. Submitted Clin Nutr.

9. Battistella FD, Widergren JT, Anderson JT, Siepler JK, Weber JC, MacColl K. A prospective, randomized trial of intravenous fat emulsion administration in trauma victims requiring total parenteral nutrition. J Trauma. 1997;43:52-8.

10. McCowen KC, Friel C, Sternberg J, et al. Hypocaloric total parenteral nutrition: effectiveness in prevention of hyperglycemia and infectious complications - a randomized clinical trial. Crit Care Med. 2000;28:3606-11.

11. Singer P, Pichard C. Reconciling divergent results of the latest parenteral nutrition studies in the ICU. Curr Opin Clin Nutr Metab Care. 2013;16:187-93.

12. Simpson F, Doig GS. Parenteral vs. enteral nutrition in the critically ill patient: a meta-analysis of trials using the intention to treat principle. Intensive Care Med. 2005;31:12-23.

13. Plurad D, Green D, Inaba K, Belzberg H, Demetriades D, Rhee P. A 6-year review of total parenteral nutrition use and association with late-onset acute respiratory distress syndrome among ventilated trauma victims. Injury. 2009;40:511-5.

14. Dissanaike S, Shelton M, Warner K, O'Keefe GE. The risk for bloodstream infections is associated with increased parenteral caloric intake in patients receiving parenteral nutrition. Crit Care. 2007;11:R114.

15. Grau T, Bonet A, Rubio M, et al. Liver dysfunction associated with artificial nutrition in critically ill patients. Crit Care. 2007;11:R10.

16. Ziegler TR. Nutrition support in critical illness - bridging the evidence gap. N Engl J Med. 2011;365:562-4.

17.• Harvey SE, Parrott F, Harrison DA, et al. Trial of the route of early nutritional support in critically ill adults. N Engl J Med. 2014;371: 1673-84. A very elegant prospective randomized double-blind multicenter study comparing enteral to parenteral nutrition in a very large population of critically ill patients showing no difference in morbidity and mortality between the two routes except more hypoglycemia in enteral feeding and more altered liver function tests in parenteral nutrition.

18. Doig GS, Simpson F, Sweetman EA, et al. Early parenteral nutrition in critically ill patients with short-term relative contraindications to early enteral nutrition: a randomized controlled trial. JAMA. 2013;309:2130-38. Supplemental parenteral nutrition is not causing any harm in patients not tolerating enteral feeding in the early stage of critical illness.

19. Heidegger CP, Berger MM, Graf S, et al. Optimization of energy provision with supplemental parenteral nutrition (SPN) improves the clinical outcome of critically ill patients: a randomized controlled clinical trial. Lancet. 2012;381:385-93. One of the unique studies using indirect calorimetry to target supplemental parenteral nutrition in patients failing to tolerate total enteral feeding.

20. Singer P, Berger MM, Van den Berghe G, Biolo G, Calder P, Forbes A. ESPEN guidelines on parenteral nutrition: intensive care. Clin Nutr. 2006;28:387-400.

21. McClave SA, Taylor BE, Martindale RG, et al. Society of Critical Care Medicine; American Society for Parenteral and Enteral 
Nutrition. Guidelines for the Provision and Assessment of Nutrition. Support Therapy in the Adult Critically Ill Patient: Society of Critical Care Medicine (SCCM) and American Society for Parenteral and Enteral Nutrition (A.S.P.E.N.). JPEN. J Parenter Enteral Nutr. 2016;40:159-211.

22. Reid CL. Poor agreement between continuous measurements of energy expenditure and routinely used prediction equations in intensive care unit patients. Clin Nutr. 2007;26:649-57.

23. Singer P, Anbar R, Cohen J, et al. The Tight Calorie Control Study (TICACOS): a prospective, randomized, controlled study of nutritional support in critically ill patients. Intensive Care Med. 2009;37: 601-9. The only (single center, pilot) study using daily indirect calorimetry measurements to assess energy requirements and target nutrition support.

24. Calder PC, Jensen GL, Koletzko BV, Singer P, Wanten GJ. Lipid emulsions in parenteral nutrition of intensive care patients: current thinking and future directions. Intensive Care Med. 2010;36:73549.

25. Pradelli L, Mayer K, Muscaritoli M, Heller AR. n-3 fatty acidenriched parenteral nutrition regimens in elective surgical and ICU patients: a meta-analysis. Crit Care. 2012;16:R184.

26. Kondrup J, Allison SP, Elia M, Vellas B, Plauth M. ESPEN guidelines for nutrition screening 2002. Clin Nutr. 2003;22:415-21.

27. Perel P, Yanagawa T, Bunn F, Roberts IG, Wentz R. Nutritional support for head-injured patients (review). Cochrane Database Syst Rev. 2006;18:CD001530.

28.• Chiang YH, Chao DP, Chu SF, et al. Early enteral nutrition and clinical outcomes of severe traumatic brain injury patients in acute stage: a multi-center cohort study. J Neurotrauma. 2012;29:75-80. Evidence to support the early enteral route in head trauma.

29. Reintam Blaser A, Poeze M, Malbrain ML, Björck M, Oudemansvan Straaten HM, Starkopf J. Gastro-Intestinal Failure Trial Group. Gastrointestinal symptoms during the first week of intensive care are associated with poor outcome: a prospective multicentre study. Intensive Care Med. 2013;39:899-909.

30. Cederholm T, Bosaeus I, Barazzoni R, et al. Diagnostic criteria for malnutrition - an ESPEN consensus statement. Clin Nutr. 2015;34: 335-40.

31. Dvir D, Cohen J, Singer P. Computerized energy balance and complications in critically ill patients: an observational study. Clin Nutr. 2005;25:37-44.

32. Heyland DK, Dhaliwal R, Drover JW, Gramlich L, Dodek P, Canadian critical care clinical practice guidelines committee. Canadian clinical practice guidelines for nutrition support in mechanically ventilated, critically ill adult patients. JPEN. 2003;27: 355-37.

33. Singer P, Hiesmayr M, Biolo G, et al. Pragmatic approach to nutrition in the ICU: expert opinion regarding which calorie protein target. Clin Nutr. 2014;33:246-51.

34. Long CL, Crosby F, Geiger JW, Kinney JM. Parenteral nutrition in the septic patient: nitrogen balance, limiting plasma amino acids, and calorie to nitrogen ratios. Am J Clin Nutr. 1976;29:380-91.

35. Frankenfield D. Energy expenditure and protein requirements after traumatic injury. Nutr Clin Pract. 2006;21:430-7.

36. Raubich JM, Ibáñez J, Marsé P, Velasco J, Bergadá J. Energy expenditure in patients with multiple organ failure. Clin Nutr. 1997; 16:307-12.
37. Anbar R, Theilla M, Kagan I, et al. Day to day variability of resting energy expenditure (REE) in multiple trauma patients. Clin Nutr. 2013;32:S28-9.

38. Frankenfield DC, Ashcraft CM. Description and prediction of resting metabolic rate after stroke and traumatic brain injury. Nutrition. 2012;28:906-11.

39. Wade CE, Kozar RA, Dyer CB, Bulger EM, Mourtzakis M, Heyland DK. Evaluation of nutrition deficits in adult and elderly trauma patients. JPEN J Parenter Enteral Nutr. 2015;39:449-55. Underfeeding trauma patients seem to be the rule in a large study.

40. Jeevanandam M, Young DH, Schiller WR. Glucose turnover, oxidation, and indices of recycling in severely traumatized patients. J Trauma. 1990;30:521-634.

41. Kagan I, Cohen J, Stein M, et al. Preemptive enteral nutrition enriched with eicosapentaenoic acid, gamma-linolenic acid and antioxidants in severe multiple trauma: a prospective, randomized, double blind study. Intensive Care Med. 2015;41:460-9. Additional enteral fish oil was not able to compensate the omega 3 depletion of cell membranes in this population.

42. Chen W, Jiang H, Zhou ZY, et al. Is omega-3 fatty acids enriched nutrition support safe for critical ill patients? A systematic review and meta-analysis. Nutrients. 2014;30(6):2148-64.

43. Plank LD, Hill GL. Similarity of changes in body composition in intensive care patients following severe sepsis or major blunt injury. Ann New York Acad Scien. 2000;904:592-602.

44. Hoffer LJ. Protein and energy provision in critical illness. Am J Clin Nutr. 2003;78:906-11.

45. Heyland D, Muscedere J, Wischmeyer PE, Cook D, Jones G, Albert M. Canadian Critical Care Trials Group: a randomized trial of glutamine and antioxidants in critically ill patients. N Engl J Med. 2013;368:1489-97.

46. Pérez-Bárcena J, Cresp C, Regueiro V, et al. Lack of effect of glutamine administration to boost the innate immune system response in trauma patients in the intensive care unit. Crit Care. 2010;14:R233.

47. Perez-Barcena J, Marse P, Zabalegui-Pérez A, et al. A randomized trial of intravenous glutamine supplementation in trauma ICU patients. Intensive Care Med. 2014;40:539-47.

48. Wischmeyer PE, Rupinder Dhaliwal R, Michele McCall M, Ziegler TR, Heyland DK. Parenteral glutamine supplementation in critical illness: a systematic review. Crit Care. 2014;18:R76.

49. Yuan WA, Yu XJ, Liu FQ, Wang HP, Wang D, Lai XP. Effects of trace element supplementation on the inflammatory response in a rabbit model of major trauma. J Trace Elem Med Biol. 2010;1:3641.

50. Berger MM, Soguel L, Shenkin A, et al. Influence of early antioxidant supplements on clinical evolution and organ function in critically ill cardiac surgery, major trauma and subarachnoid hemorrhage patients. Crit Care. 2008;12:R101.

51. Berger MM, Shenkin A. Trace element requirements in critically ill burned patients. J Trace Elem Med Biol. 2008;22:166.

52. Beath SV, Kelly DA. Total parenteral nutrition-induced cholestasis: prevention and management. Clin Liver Dis. 2016;20:159-76. 